\title{
Repensando o Complexo de Édipo e a Formação do Superego na Contemporaneidade
}

\author{
Sandra Aparecida Serra Zanetti \\ Universidade Estadual de Londrina, Londrina, \\ PR, Brasil.
}

\author{
Julia Archangelo Guimarães Höfig \\ Universidade Estadual de Londrina, Londrina, \\ PR, Brasil.
}

Resumo: O presente artigo é um estudo teórico acerca da evolução do conceito de complexo de Édipo, em torno do qual se organiza a vida psíquica dos seres humanos. A reflexão em pauta pretende demonstrar o modo como o constructo pode estar sofrendo influências distintas, tendo em vista as mudanças socioculturais desde a modernidade e, consequentemente, nas formas de organização da família. Para tal, foram utilizados textos contemporâneos que trazem considerações sobre possíveis reformulações deste conceito e, posteriormente, contribuições do referencial teórico kaesiano para a reflexão sobre o tema. Sabe-se que a sociedade contemporânea convive com a ausência de autoridades rígidas e regras ditadas, o que convoca o sujeito a construir suas próprias referências e elaborar suas próprias normas. Nesta nova configuração, o poder encontra-se horizontalizado, não correspondendo mais ao pai, o que pode acarretar em fragilidades e interferir numa organização psíquica em torno do complexo de Édipo e da formação do superego, levando ao afloramento de mecanismos de defesas pobres em capacidades de simbolização. Palavras-chave: Complexo de Édipo, Superego, Contemporaneidade, Família.

\section{Rethinking the Oedipus Complex and the Superego Formation in the Contemporaneity}

\begin{abstract}
This article aims to present a theoretical study about the transformation of the concept of the Oedipus complex, main organizer of the psychic life of human beings. This reflection will demonstrate how the construct may be suffering distinct influences, such as socio-cultural changes, since modernity and, consequently, changes the forms of family organization. To this end, recent articles were used in order to bring new considerations of possible reformulations of the Oedipus complex. Later in this article, contributions of Kaës work were used to expand our reflections about the topic. Contemporaneity faces an absence of authorities and rules, which summons individuals to build their own references and draw up their own rules. In this new configuration, the authority is no longer represented by the image of the father, which can result in weakness and interferes with a psychic organization around the Oedipus complex and around the superego formation, leading to upwelling poor defense mechanisms in symbolization capabilities.
\end{abstract}

Keywords: Oedipus Complex, Superego, Contemporaneity, Family. 


\title{
Repensando el Complejo de Edipo y la Formación del Superyó en la Contemporaneidad
}

\begin{abstract}
Resumen: Este artículo es un estudio teórico sobre la evolución del concepto del complejo de Edipo, en torno al cual se organiza la vida psíquica de los seres humanos. La reflexión sobre el tema tiene como objetivo demostrar cómo la construcción puede estar sufriendo influencias distintas, dados los cambios socio-culturales desde la modernidad y, en consecuencia, en las formas de organización familiar. Paras tal, fueron utilizados textos contemporáneos que traen consideraciones sobre posibles reformulaciones de este concepto y, posteriormente, contribuciones del referencial teórico kaesiano para la reflexión sobre el tema. Se sabe que la sociedad contemporánea convive con la ausencia de autoridades rígidas y reglas dictadas, lo que convoca a la persona a construir sus propias referencias y elaborar sus propias reglas. En esta nueva configuración, el poder se encuentra horizontalizado y no se corresponde más al padre, lo que puede provocar debilidad e interferir con una organización psíquica en torno al complejo de Edipo y a la formación del superyó, que conduce a la surgimiento de mecanismos de defensa pobres en las capacidades de simbolización.

Palabras clave: Complejo de Edipo, Superyó, Contemporaneidad, Familia.
\end{abstract}

\section{Introdução}

O presente artigo trata do estudo sobre a evolução do conceito de complexo de Édipo cunhado por Freud (1924/1969), central em sua obra, em torno do qual se organiza a vida psíquica dos seres humanos, a construção das neuroses e a sexualidade. $O$ aspecto central na formulação deste texto é o fato de que o complexo de Édipo e seu herdeiro, o superego, são matrizes conceituais conjecturadas por Freud (1924/1969), que foram organizadas com base nas condições socioculturais e econômicas da época. Freud já sublinhava a influência que exercia sobre essa forma de se estruturar o psiquismo - em torno do complexo de Édipo -, uma organização social hierárquica, centralizada na figura do pai como o responsável por assegurar o patrimônio familiar e a inserção da criança na cultura, estabelecendo na família uma ordem que era representante dos interditos e das leis da civilização. A reflexão em pauta pretende demonstrar o modo como o fenômeno do complexo de Édipo pode estar sofrendo influências socioculturais, distintas daquela preconizada por Freud (1924/1969), tendo em vista as mudanças na vida moderna e contemporânea, especialmente nas configurações familiares.

Inicialmente, cabe retomar a explicação freudiana sobre o complexo de Édipo para, em seguida, realizar reflexões sobre textos contemporâneos que trazem considerações sobre reformulações deste construto para, finalmente, baseado no referencial teórico kaesiano, discutir a transformação do fenômeno complexo de Édipo, delineando uma perspectiva para pensar na organização do psiquismo na atualidade.

\section{A teoria sobre o complexo de Édipo}

Foi em 1897 que Freud inaugura a ideia de um complexo, de Édipo, numa carta a Fliess. Contudo, só mais tardiamente, após a formulação da pulsão de morte e, a partir de sua articulação com o conceito de castração, a ideia ganharia uma dimensão conceitual, que, embora central na obra freudiana, receberá apenas um texto específico em dedicação ao tema: "A Dissolução do Complexo de Édipo", de 1924. (Moreira, 2004). Nessa obra, Freud (1924/1969) dedica-se a apresentar a tese de que, quando a criança adentra a fase fálica, por volta dos três anos e meio, entra em cena um "conjunto organizado de desejos amorosos e hostis que a criança sente em relação aos pais" (Laplanche, 2004, p. 77). Sob sua forma dita positiva, o complexo de Édipo apresenta-se como na história de Édipo-Rei: há um desejo pela morte do rival que é personagem do mesmo sexo e desejo sexual pela personagem do sexo oposto (Laplanche, 2004); em sua forma negativa, temos o contrário, em termos das personagens de desejo e rivalidade. 
Mais detalhadamente, no caso do menino, quando adentra na fase fálica, dirige o seu interesse para seu órgão genital, fato que revela ao manipula-lo frequentemente. Então, descobrirá que os adultos não o aprovam neste ato, com base em ameaças, inclusive de que essa sua parte do corpo tão valorizada poderá lhe ser retirada caso não deixe de manipulá-la. Freud (1924/1969) acentua que esta ameaça de castração é o que ocasiona a destruição da organização genital fálica da criança, o que, somado à observação dos órgãos sexuais femininos, poderá causar no menino grande angústia. O menino, até então apaixonado pela mãe e em rivalidade clara com o pai, recua a esse amor diante do medo de ser castrado, visto que o pai é um rival muito superior a ele. Nas palavras de Freud (1924/1969):

Se a satisfação do amor no campo do complexo de Édipo deve custar à criança o pênis, está fadado a surgir um conflito entre seu interesse narcísico nessa parte de seu corpo e a catexia libidinal de seus objetos parentais. Nesse conflito, triunfa normalmente a primeira dessas forças: o ego da criança volta as costas ao complexo de Édipo. [...] As catexias de objeto são abandonadas e substituídas por identificações. A autoridade do pai ou dos pais é introjetada no ego e aí forma o núcleo do superego, que assume a severidade do pai $\mathrm{e}$ perpetua a proibição deste contra o incesto, defendendo assim o ego do retorno da catexia libidinal (Freud, 1924/1969, p. 196, grifos nossos).

Cabe salientar que se trata de uma vivência decisiva para a organização da vida psíquica posterior, principalmente porque, como Freud (1924/1969) ressalta, há uma consequência de grande importância para a formação do aparelho psíquico nesta etapa da vida: o surgimento do superego -instância do aparelho psíquico responsável por exercer o papel de um juiz ou censor relativamente ao ego, que se constitui a partir da interiorização das interdições parentais no desenvolvimento do complexo de Édipo (Laplanche, 2004). Isso acontece tanto no caso do menino, quanto no da menina, já que, para o autor, "o clitóris inicialmente comporta-se exatamente como um pênis, porém quando ela efetua uma comparação com um companheiro de brinquedos do outro sexo, percebe que 'se saiu mal' e sente isso como uma injustiça feita a ela e como fundamento para inferioridade" (Freud, 1924/1969, p. 197-198).
A menina tenderá a consolar-se com a expectativa de que, quando ficar mais velha, terá um órgão genital tão grande quanto do menino. Ela não entende a sua situação como se tivesse sido castrada, mas como um fato consumado, ao passo que o menino teme a possibilidade disso acontecer, vendo que a menina não possui o pênis. Freud (1924/1969) compreende que o complexo de Édipo na menina é muito mais simples porque raramente vai além da questão de assumir o lugar da mãe e adotar uma atitude feminina para com o pai. A insatisfação com o tamanho de seu órgão genital se resolve por uma via de compensação, em que o pênis é equacionado a um bebê. "Seu complexo de Édipo culmina em um desejo, mantido por muito tempo, de receber do pai um bebê como presente - dar-lhe um filho" (p. 198). A resolução no caso da menina envolve um complexo de Édipo que será abandonado na medida em que ela percebe que seus desejos - possuir um pênis e um filho - jamais se realizarão. Contudo, permanecerão fortemente catexizados no inconsciente e ajudarão a preparar a menina para seu possível papel futuro de mãe (Freud, 1924/1969).

É importante chamar atenção nessa construção para o caráter de organização hierárquica sustentando a formação familiar, que está por detrás dessas ideias. A figura de autoridade e admiração do pai é central e organiza a dinâmica psíquica das crianças. Entretanto, cabe salientar que não é mais dessa forma, ou somente dessa forma, que encontramos compostas as famílias na atualidade.

\section{Repensando o complexo}

Baseando-se no trabalho de Lévi-Strauss (1956), Roudinesco (2003) afirma que foi no seio das duas grandes ordens, a do biológico, através da diferença sexual e a do simbólico, através da proibição do incesto e outros interditos, que se desenrolaram durante séculos, não apenas as transformações na instituição familiar, mas também as modificações do olhar para ela voltado ao longo das gerações. No entanto, considera, ainda a partir de Lévi-Strauss, que, durante essas transformações, foi possível perceber uma variedade de modalidades de arranjos e organização familiares, embora nem todas duradouras, o que salienta a necessidade de não somente definir a família sob o ponto de vista antropológico, mas também saber qual a sua história, para que se possa interpretar as mudanças atuais. 
Setton (2002) assegura que a família é uma instituição que evolui conforme as conjunturas socioculturais e revela um poder de adaptação e uma constante resistência em face das mudanças de cada período. Roudinesco (2003), analisando essas mudanças, entende que podemos distinguir três grandes períodos na evolução da família.

A primeira fase se consistiu na família denominada tradicional, na qual a função estava, acima de tudo, em assegurar a transmissão de um patrimônio. Nessa primeira fase, os casamentos eram arranjados entre os pais, sem que a vida sexual e afetiva dos futuros esposos, unidos em idade precoce, em geral, fosse levada em conta. Nessa perspectiva, a célula familiar repousava em uma ordem submetida a uma autoridade patriarcal, "verdadeira transposição da monarquia de direito divino” (p. 19). Numa segunda fase, a chamada família moderna se tornou "o receptáculo de uma lógica afetiva cujo modelo se impõe entre o final do século XVIII e meados do XX" (p. 19). Essa célula familiar estava fundamentada no amor romântico e sancionava a reciprocidade dos sentimentos dos desejos sexuais por intermédio do casamento. Nessa fase houve também a valorização da divisão do trabalho entre os esposos, "fazendo ao mesmo tempo do filho um sujeito cuja sua educação sua nação é encarregada de assegurar" (p. 19). Aqui, a atribuição da autoridade tornou-se um motivo de uma divisão incessante entre o Estado e os pais. E, finalmente, na terceira fase, a partir dos anos 1960, impõe-se a família denominada contemporânea ou pós-moderna, caracterizada basicamente pela união de dois indivíduos em busca de relações íntimas ou realização sexual (Roudinesco, 2003) e é esta a organização que faz repensar os construtos teóricos de Freud (1924/1969).

Numa análise mais detalhada, observa-se que mudanças profundas separam a família tradicional da família contemporânea, tendo em vista a demarcação dos processos socioculturais que contribuíram e sustentaram essas mudanças. Roudinesco (2003) aponta que a flexibilidade permitida pela sociedade ao redor da instância do casamento e as técnicas que possibilitaram à mulher a escolha de gerar filhos, disponibilizaram um grau de liberdade que chega a ameaçar a família contemporânea enquanto instituição.

Instaurado como um direito pelos revolucionários em 1792, restrito pelo Código Napoleônico em 1804, proibido sob a Restauração a partir de 1816, restabelecido finalmente pela República em 1884, "o divórcio sempre foi condenado moralmente pelos conservadores, que temiam que sua propagação resultasse na morte da família, na abolição do sentimento da alteridade e, em última instância, no aniquilamento de toda vida social" (Roudinesco, 2003, p. 152). Neste processo, o casamento, que sempre foi considerado como um sacramento pelo direito canônico, depois como necessário à legitimação dos cônjuges e de seus filhos no direito laico, perdeu efetivamente sua força simbólica à medida que aumentava o número dos divórcios. Segundo esta autora, o casamento passou a ser cada vez mais assimilado como um rito festivo que apenas assinala um contrato mais ou menos duradouro entre duas pessoas.

Roudinesco (2003) também aponta que, desde sempre, os homens tiveram que aceitar recorrer às mulheres para "fabricar" seus filhos e lhes transmitir seus nomes. Cuidaram, por isso, de regulamentar e dominar o corpo de suas companheiras. No entanto, logo depois da Segunda Guerra Mundial, as técnicas de regulamentação dos nascimentos substituíram progressivamente o coitus interruptos e o uso de preservativos masculinos. Através da ajuda do planejamento familiar ou recorrendo às diferentes técnicas de impedir a fecundação, as mulheres conquistaram, ao preço de lutas difíceis, direitos e poderes que lhes permitiram não apenas reduzir a dominação masculina, mas inverter seu curso.

$\mathrm{Na}$ passagem da "soberania divina do pai", na qual a família esteve baseada durante séculos, para a "irrupção do feminino", no século XVIII, com a qual esta Instituição foi desafiada, a autora citada se pergunta se estaremos assistindo ao nascimento de uma onipotência do materno que viria definitivamente aniquilar o antigo poder do masculino e do paterno em benefício de uma sociedade comunitarista. Isso porque a ordem familiar econômico-burguesa repousava em três fundamentos: a autoridade do pai, a subordinação das mulheres e a dependência dos filhos. E justamente outorgar à mãe e à maternidade um lugar considerável era proporcionar um meio de controlar aquilo que, no imaginário da sociedade, corre o risco de desembocar em uma perigosa irrupção do feminino. Ou seja, aquilo que, sem o devido controle da função materna, se transformaria numa sexualidade devastadora: "A mulher deve acima de tudo ser mãe, a fim de que o corpo social esteja em condições de resistir à tirania de um gozo feminino capaz, pensa-se, de eliminar a diferença dos sexos" (Roudinesco, 2003, p. 38). 
Tudo se passa como se esse perigo representasse a suspensão da ordem paterna. E sem essa lei simbólica, para a autora, "a família mutilada das sociedades pós-industriais seria, dizem, pervertida em sua própria função de célula de base da sociedade" (Roudinesco, 2003, p. 10). Atualmente, podemos percebê-las entregue aos mais variados padrões - monoparental, homoparental, recomposta, desconstruída, gerada artificialmente, além da nuclear - de maneira que esta instituição estaria incapacitada de transmitir seus próprios valores, um de seus mais importantes alicerces. O que faria com que o Ocidente judaico-cristão ou, ainda, a democracia republicana, ressalta Roudinesco (2003), estivessem ameaçados de decomposição, por consequência.

À vista de tudo, esta autora considera que a família contemporânea se assemelha a uma rede fraterna, sem hierarquia nem autoridade, e na qual cada um se sente autônomo ou funcionando. Nesta, o casamento perdeu todo seu valor simbólico de outrora, tornando-se apenas um tipo de união, mais ou menos duradoura, que protege os cônjuges de eventuais desordens do mundo. Os filhos são cada vez mais concebidos fora dos laços matrimoniais e assistem às núpcias e divórcios de seus pais. Em lugar da divinização, a família contemporânea se pretende frágil, neurótica consciente de sua desordem, mas preocupada em recriar laços com um equilíbrio que não pode ser proporcionado pela vida social. "Assim fez brotar de seu próprio enfraquecimento um vigor inesperado. Construída, desconstruída, reconstruída, recuperou sua alma na busca de uma soberania alquebrada ou incerta" (Roudinesco, 2003, p. 153). Nas palavras da autora:

De agora em diante esta não será mais vista como uma estrutura do parentesco que restaura a autoridade derrotada do pai, ou sintetizando a passagem da natureza à cultura através de interditos e das funções simbólicas, mas como um lugar de poderes descentralizado e de múltiplas aparências. [...] Em lugar daquela induzida pelo mito edipiano, foi instituída outra, horizontal e múltipla, inventada pelo individualismo moderno (p. 155).

Nessa passagem, Roudinesco (2003) aponta o quanto esta nova organização da família, contemporânea tem o poder de desorganizar o modo como se estabelecia o complexo de Édipo. Ela conclui, inclu- sive, que no lugar daquela induzida pelo mito edipiano, apareceu outra: inventada pelo individualismo.

Como já dito anteriormente, essas mudanças observadas na família retratam mudanças ocorridas na organização sociocultural, a qual daremos ênfase mais adiante. O que é interessante notar neste momento é que a percepção destas transformações e rearranjos na família levaram pesquisadores a repensar o complexo de Édipo.

Há autores, como Nicolson (2012), que asseguram que o complexo de Édipo é um elemento organizador do psiquismo e que continua vivo, sendo uma metáfora para explicar as relações familiares e sua dinâmica. Simões (2013) salienta que a família é um fenômeno universal enquanto estrutura, pois é nela que a ordem social se instaura, através da transmissão dos interditos que são necessários à continuação da sociedade, impedindo que a família se encerre em si mesma. A autora entende, portanto, que a família continua sendo sede para a organização neurótica dos indivíduos, partilhando das leis e dos interditos.

Steele (2010) assinala que transformações da teoria freudiana envolvem repensar a relação tríade que se estabelece entre mãe, pai e bebê, ou seja, o complexo de Édipo precoce. A autora explica que a resolução do Édipo está em uma diminuição nos sentimentos ambíguos de desejo em relação a um dos pais e sentimentos agressivos em relação ao outro; identificação com o genitor do mesmo sexo; e estabelecimento de um superego moral. Considera que muitos psicanalistas falaram sobre a importância do pai no processo de individuação e separação da mãe, e em abrir novas perspectivas para a criança, mas algumas pesquisas apontaram que a relação tríade começa muito antes da entrada no Édipo.

Balsam (2010), por sua vez, considera que o fenômeno passou por múltiplas transformações, já que existem diferenças na cultura de cada país, assim como houve mudanças sociais na contemporaneidade. A autora aponta que muitos - se não a maioria - dos psicanalistas de hoje tendem a desafiar a afirmação de Freud sobre a centralidade absoluta do complexo de Édipo na vida psicológica cotidiana. Contudo, considera que o complexo de Édipo deve ser entendido como uma medida de capacidade avançada para integrar tanto uma figura materna quanto a figura paterna na vida interior, e que este fenômeno ainda está entre nós, se tivermos olhos para vê-lo e ouvidos para ouvi-lo. 
Em outros artigos, autores mais ousados se dispõem a pensar mais profundamente sobre as mudanças no complexo. Richard (2014) discute a hipótese de que, na sociedade contemporânea, o complexo de Édipo é mais complexo, embora continue exercendo a influência de um organizador central para a psique. Propõe uma compreensão com base em antropólogos, especialmente François e Heritier, e salienta a importância de se restabelecer o debate a partir de uma reflexão sobre a função paterna atual. Há diversas formas da assunção ou não da função paterna em nossa sociedade, e por isso estabelece que o triângulo edípico pode assumir várias formas também.

Berger (2013) observa que o funcionamento psíquico de algumas crianças e adolescentes foi alterado sob a influência de modificações que surgiram na estrutura familiar, na dissolução de nossas autoridades superegoicas coletivas, e na recusa em reconhecer a inevitabilidade da finitude, sob a pressão de fatores tecnológicos, como a Internet. Savietto e Cardoso (2009) concordam, assinalando que vivemos em uma época em que se busca o prazer ilimitado, sem cessar.

As autoras supracitadas resgatam Bauman (2001), para quem vivemos na ordem da instabilidade, vulnerabilidade, incerteza e insegurança, sobrevivendo à mercê da única instituição que se mantém estável: a econômica. Outras instituições de poder como o Estado e a família, se "liquefizeram-se", transformando-se em instáveis, e mutáveis. A família tradicional e hierárquica dos tempos de Freud definia os indivíduos de acordo com sua idade, sexo e ditava as condutas "certas" e "erradas", asseguram Savietto e Cardoso (2009). Esta família tem dado espaço a uma "família igualitária", na qual convivemos com a ausência de autoridades rígidas e regras ditadas e fixas. Desta forma, o sujeito da contemporaneidade deve e é convocado a construir suas próprias referências e elaborar suas próprias normas. Nesta nova configuração familiar, o poder encontra-se horizontalizado, não correspondendo mais ao pai.

Druzhinenko-Silhan (2013) se questiona se estamos mesmo vivenciando a morte do mito de Freud ou se as mudanças observadas refletem um processo que está se complexificando. Por meio de um estudo realizado em diversos países, conclui que o indivíduo da contemporaneidade tem que enfrentar um problema que não existia anteriormente, em um tempo em que o discurso dominante criava e mantinha "naturalmente" um lugar a qual poderíamos nos referir. Hoje, o problema é que o indivíduo deve se sujeitar a criar um local de referência, para que o pai possa voltar ao pedestal ocupado por uma criança. A sociedade liberal tenta apagar as diferenças geracionais e de gênero, que são constitutivas. Promove uma parentalidade democrática, sem conflitos, na qual não há mais mães e pais.

Simões (2013) ressalva que, no novo perfil social de família, exige-se que o pai fique mais próximo dos filhos e passe a desempenhar funções paternas, mas também maternas, que estão mais relacionadas com questões de caráter emocional. Por conta destas mudanças sociais, de costumes e de valores, altera-se a construção psíquica, dos sintomas e dos relacionamentos. Na sociedade contemporânea os pais têm como lei e principal objetivo a felicidade do filho. Este novo imperativo pode assumir um efeito sintomático na criança. Deste modo, o ideal de Ego deixa de ser vinculado às leis de dever e bem-estar coletivo para operar na necessidade de se obter felicidade. A autora concorda que os desafios atuais para o pai, para a mãe e para a criança são marcados pelo excesso de informação, simultaneidade e imediatez, excesso de trabalho e consumo. Enfatiza que não nos sobra espaço para a falta, o sofrimento e o luto. Como as frustrações são rejeitadas na sociedade contemporânea e ficam sem um contorno e sustentação dos pais ao modo como o filho deve conduzir, todo incômodo ou sofrimento é lançado para fora, desligando os afetos de suas representações. Este processo esvazia o mundo interno e as possibilidades simbólicas.

Fidelis e Pereira (2012) entendem, concordando com Simões (2013), que as condições subjetivas se mostram individuais, com recusas de castração simbólica. Portanto, como condição da contemporaneidade, encontramos o declínio da função paterna e, neste sentido, entendem que os adolescentes são um retrato fiel da sociedade. Isto porque são pessoas que usufruem das liberdades adultas, sem se responsabilizar pelas mesmas. Este fenômeno ocorre porque estamos vivendo em uma época sem referências, sem delineamento, na qual o "ser jovem" virou o ideal da sociedade e, portanto, os sujeitos se desfazem do passado, e o adolescente passa a ser o modelo para o adulto, o que, como consequência, desautoriza os pais. Costa (2012) acrescenta que, na sociedade contemporânea, frisamos a necessidade sobre a igualdade entre os indivíduos, perpetuando a ideia de que todos possuem o mesmo valor e isto se aplica na 
família também, o que culmina igualmente na desautorização dos pais.

\section{Transformações sociais e psíquicas numa vertente kaesiana}

Em termos gerais, podemos pensar que a contemporaneidade se caracteriza por apresentar valores paradoxais e descontínuos (Kaës, 2005a,b) baseados em leis de troca do mercado, na imprevisibilidade e na necessidade de controle (Bauman, 2001), em face de um dinamismo sem precedentes (Giddens, 1991, 2007) de sorte que perecem e não favorecem a transformação própria do simbólico (Baudrillard, 2007).

Trata-se de uma sociedade na qual nada se exclui, e a liberdade e a ilimitada variedade de possibilidades permitem a sensação de estar solto e sem qualquer controle, sem qualquer norma que garanta um mínimo sobre o destino das relações, igualmente soltas. Uma sociedade na qual os interesses pessoais sobressaem-se aos do grupo, na qual o individualismo assume o lugar das grandes narrativas, da memória coletiva, do bem comum, público e durável (Giddens, 1991). Em poucas palavras, na qual o ser humano, através das novas organizações subjetivas, busca proteção. Todo o tipo de "solidez" foi trocado por "fluidez" (Bauman, 2001, 2004, 2009), e não existem mais normas ou contratos separando o legítimo do não legítimo, o seguro do não seguro, o justo do não justo. Caindo as "grandes certezas" que davam rumo e sentido ao mundo, diante de um futuro imprevisível, cada vez mais se sente que tudo precisa ser móvel, flexível e reinventável, como sublinha Lipovetsky (2004).

Atualmente, tudo se equivale, tudo pode ser trocado, tudo é indiferente ou indiferenciado, porque a cultura se caracteriza pela recusa de todo o tipo de cristalização dos códigos e de ancoragem, afirma Kaës (2005b). O valor de liberdade que sustenta essas recusas por normas padronizadas levou à complexidade de um pensamento não linear capaz de admitir paradoxos e incertezas, além da instabilidade entre a ordem e a desordem (Kaës, 2005b).

Consideramos que Kaës (2005a,b) seja um autor capaz de promover a construção de um pensamento que articula, de modo complexo e adequado, o social ao psíquico; tal como se faz necessário quando se propõem a reflexão sobre um fenômeno que envolve estes dois polos, como é o complexo de Édipo e seu herdeiro, o superego. Seu pensamento parte do movimento de desestabilização que se iniciou com a modernidade. De acordo com o autor, como um modo de civilização que se opunha ao mundo da tradição, a modernidade criou, em última instância, uma cultura crítica com relação às crenças e certezas sustentadas pelos mitos, pela religião, pelos ideais coletivos e pelas hierarquias sociais, os quais estabeleciam um sistema estável de sentidos e valores. Por consequência, sua análise pretende defender a existência de falhas nas garantias ${ }^{1}$ metassociais que se refletem em falhas nas garantias metapsíquicas, como será explicado.

Com base em Freud (1930/2006), Kaës (2005ab) concebe o nascimento de dificuldades em torno da estruturação do psiquismo, na atualidade. Para o autor (2005b), o mundo tradicional era o responsável pelas garantias metassociais da sociedade, ou seja, o responsável por um "enquadramento da vida social e cultural, os grandes processos de regulação da vida coletiva: mitos e ideologias; crenças e religiões; autoridades e hierarquia; instituições culturais e políticas" (p. 243, tradução livre do autor), as grandes estruturas de regulação que asseguram a ordem social e cultural numa sociedade, mas também a organização da estruturação psíquica (Kaës, 2009). E, nesse sentido, na contemporaneidade, pelo oposto, perde-se em valores e princípios tradicionais, institucionalizados e hierarquizados, e consequentemente, perde-se também em organizadores da vida psíquica, conforme o autor.

Não se trata de cedermos à ilusão da morte das ideologias, ele afirma, mas de entendermos que o que desapareceram foram as formas instituídas das ideologias e dos mitos, e que essa perda da estabilidade em torno de crenças e valores influencia na estruturação do psiquismo. Vale ressaltar que a nossa ideia aqui não é a de adentrar num espaço de idealização das estruturas do passado, nem a do autor, supomos, mas de compreender movimentações socioculturais e suas possíveis consequências para a organização do psiquismo, vulnerabilidades e fragilidades que o ser humano tem experimentado por conta desta nova organização.

Logo, seguindo o pensamento do autor, esses enquadramentos metassociais se definiam por garantir uma estabilidade às formações sociais e por adquirir uma legitimidade incontestável. Quando

${ }^{1}$ O termo utilizado pelo autor é "garant", que optamos por traduzir como "garantia". 
as garantias metassociais passaram a se mostrar falhas, ou quando se transformaram sob o efeito da industrialização, da urbanização e dos movimentos migratórios induzidos pelas mutações, as sociedades industriais passaram a sofrer os efeitos de instabilidades graves. Quando as grandes ideologias e crenças no progresso não mais sustentaram as certezas em termos do futuro, os sistemas de representações e os valores, mas também as leis e os interditos, que regulamentam as relações sociais e interpessoais, tornaram-se instáveis, contraditórias e inoperantes. Desqualificaram-se, enfatiza Kaës (2005b).

Por conseguinte, entendemos que falhas nas garantias metassociais representam uma movimentação em torno das representações sociais que regravam as relações sociais e interpessoais baseadas nas leis e nos interditos. E a relação dessas garantias metassociais com as garantias metapsíquicas é que as primeiras eram capazes de garantir as segundas: reparos identificatórios, ideais comuns, representações simbólicas e imaginárias, alianças inconscientes, pactos e contratos, todos necessários à estruturação do psiquismo (Kaës, 2005b).

Na leitura de Kaës (2005a,b), em O mal-estar da civilização, Freud (1930/2006) coloca em evidência justamente a necessidade da renúncia à realização direta dos fins pulsionais para que o indivíduo possa se formar e se manter; um contrato em que o homem renuncia a uma parte da felicidade para trocá-la por segurança. Como Freud (1930/2006) salienta, a vida civilizada torna-se possível somente porque o conjunto é mais poderoso do que cada indivíduo particular e, principalmente, o conjunto em face de um único indivíduo. Quando o poder do coletivo se opõe à violência individual, a comunidade não somente limita os prazeres, mas se protege "contra a violência do indivíduo, impõe a necessidade e torna possível o amor" (Kaës, 2005a, p. 57).

Da obra de Freud (1930/2006), o conjunto de regras que regulamenta a relação entre os homens é frisado por Kaës (2005b), porque para ele é dessa maneira que as leis e os interditos garantem não só a vida em comunidade, mas, a partir do trabalho de civilização, também a sublimação e, com isso, "a segurança necessária para a formação do pré-consciente, para o trabalho do pensamento e a manutenção dos vínculos" (Kaës, 2005a, p. 57). E, se tal tentativa se fizer falha, o conjunto de regras poderia ser submetido à arbitrariedade de um indivíduo psiquicamente mais forte, que regulamentaria os sentidos e pulsões instintivas ao seu próprio interesse, conforme destaca Freud (1930/2006) e como de fato ocorreu. Kaës (2005b) compreende que o texto de Freud (1930/2006) foi profético, nesse sentido, prevendo grandes desestruturações sociais e culturais, como foi o fascismo e o nazismo. Tais atrocidades só foram possíveis, observa Kaës (2005b), porque esses líderes não encontraram algo mais forte do que eles, isto é, um conjunto cultural sólido, sustentado por suas regulamentações.

Disso podemos depreender que o contrato civilizatório, composto por um conjunto de crenças e regras bem instituídas, é a base não somente para a vida em civilização, mas da possibilidade de se pensar e elaborar, trabalhar e amar. No entanto, o autor defende que esse contrato, desde a modernidade, foi sofrendo movimentações e modificações, causando desorganizações sociais, culturais e sofrimento psíquicos.

Aprofundando-nos em seu pensamento, são sobre essas bases falhas, desregramento ou defeitos nas garantias metassociais que se transformam em falhas ou defeitos das garantias metapsíquicas, afetando diretamente a estruturação e o desenvolvimento da vida psíquica de cada sujeito. Ou seja, o autor propõe que movimentações em torno dos valores e crenças instituídas, das representações sociais (garantias metassociais), interferem na manutenção estável das leis e dos interditos fundamentais e dos contratos intersubjetivos (garantias metapsíquicas), concebidos pelo autor como suportes para a estruturação do psiquismo. Em outras palavras, as estruturas metassociais sustentam as estruturas metapsíquicas, responsáveis pelos princípios organizadores da psique individual, além das condições intersubjetivas (Kaës, 2009).

Ainda que uma parte da realidade psíquica inconsciente escape a toda determinação social ou intersubjetiva, a intenção de Kaës (2005b) é a de mostrar que a vida psíquica somente pode se desenvolver sobre uma base de exigência de trabalho psíquico, que impõe ao psiquismo sua inscrição nos vínculos intersubjetivos primários e nos vínculos sociais. Assim, entende que as garantias metapsíquicas são as formações e os processos ambientais psíquicos sobre os quais se sustentam e se estruturam o psiquismo de cada sujeito. Essencialmente, são os interditos fundamentais e os contratos intersubjetivos que exercem a função "meta" para cada psiquismo 
singular e para todos os sujeitos de um conjunto. Enfatiza o autor:

O prefixo meta indica uma mudança de lugar, de condição (metabolismo), de local (metáfora) ou de nível de reflexão (metafísica, metalinguagem, metapsicologia) ou ainda a sucessão no tempo ou no espaço. O que me interessa na preposição meta são os dispositivos de fundo que enquadram os processos ou as formações que observamos. É neste sentido que eu falo da organização metapsíquica (Kaës, 2009, p. 26, tradução livre do autor).

Nessa perspectiva, compreendemos que o prefixo "meta" indica, justamente, um posicionamento de fundo estruturante, indicando aquilo que sustenta, garantido a existência do que ampara por sua função sustentadora. As garantias metapsíquicas, na realidade, podem ser descritas sob diversos pontos de vistas, segundo Kaës (2005b); todavia, esse autor, que se dedicou amplamente a estudar os grupos e seus funcionamentos, escolheu descrevê-los centrados sobre os contratos, dentro dos quais estão inseridos tanto as leis e os interditos, quanto os pactos e as alianças.

As alianças, os contratos e os pactos que correspondem à estruturação do psiquismo são aquelas relacionadas ao pacto denegativo, ao contrato de renúncia à realização direta dos fins pulsionais e ao contrato narcísico. Tais garantias metapsíquicas são preexistentes ao nascimento de uma criança e elas a "amarram" e "reamarram" aos seus contemporâneos. Neste texto, apresentaremos brevemente o pacto denegativo e o contrato narcísico, pois daremos ênfase ao contrato de renúncia à realização direta dos fins pulsionais, já que este contrato se relaciona diretamente com a estruturação do complexo de Édipo.

Embora o pacto denegativo tenha uma função defensiva e comporte uma deriva patológica, Kaës (2005b) salienta que ele tem a função de manter unida uma família, um grupo ou um casal, porque se trata justamente do pacto inconsciente entre os psiquismos de manter sob recalque tudo aquilo que não pode ser tolerado pelos membros da união. Assim, é um pacto organizador dos vínculos, mas de caráter defensivo (Kaës, 2014). Para o autor, todo o espaço psíquico comum e compartilhado pelos membros de uma mesma família, de um casal, de um grupo ou de uma instituição contém formações metapsíquicas desse tipo, e essas formações (pactos, acordos e alianças) são sensíveis às estruturas profundas da vida social e cultural (Kaës, 2005b).

Importante considerar, antes de seguirmos, que todas essas conceituações se apoiam num arcabouço teórico desenvolvido pelo autor ao longo de sua obra, em que Kaës (2011) supõe a existência de um campo intersubjetivo próprio às formações grupais, no qual se organiza um espaço comum, conjunto e compartilhado, que compreende a existência de processos específicos, por meio dos quais os sujeitos se constituem em termos subjetivos e também parte de seu inconsciente. De forma sucinta, de acordo com Fernandes (2004), fundamentando-se em Kaës, um grupo organiza-se a partir de alianças inconscientes, de pactos denegativos e de contratos e pactos narcísicos. Cada um deles tem o poder de reforçar certos processos, certas funções ou certas estruturas das quais os sujeitos retiram um benefício tal que a ligação os mantém unidos. Destaca a autora:

Aliança Inconsciente é pensada como uma formação psíquica intersubjetiva construída pelos sujeitos de um vínculo para reforçar, em cada um deles, certos processos, certas funções, ou certas estruturas das quais eles tiram um benefício tal que a ligação que os mantêm junto, toma para sua vida psíquica um valor decisivo. O conjunto assim ligado não tem sua realidade psíquica a não ser pelas alianças, contratos e pactos que os sujeitos estabelecem e que seu lugar no conjunto os obriga a manter. Elas estão a serviço de uma função recalcante, e, além disso, de um sobre-recalque, como se fosse um redobramento do recalque, na medida em que elas se manifestam não somente sobre os conteúdos inconscientes, mas sobre a própria aliança (Fernandes, 2004, § 23).

Com relação ao contrato narcísico (Aulagnier, 1979), de acordo com Kaës (2005b), é por meio desse contrato que cada recém-nascido vem ao mundo como portador da missão de assegurar a continuidade da família, de um modo particular, assegurando assim um lugar nesse grupo e do qual receberá investimento narcísico. A principal função desse contrato, o autor explica, é a de manter a continuidade de investimento de autoconservação em cada sujeito e no conjunto do qual faz parte. Além disso, possibilita ao grupo familiar manter uma ideia de temporalidade, de projeto e de futuro, na medida em que cada membro do conjunto 
se responsabiliza por manter vivo o passado e o futuro dos valores e crenças particulares, daquilo que dá singularidade àquela formação familiar. Porém, essa dimensão de temporalidade, de permanência no tempo, o autor sublinha, está em desacordo com as condições de existências contemporâneas: cada vez mais o futuro se torna imprevisível e cada vez menos a tradição tem influência sobre o presente e o futuro.

Em uma sociedade pautada na globalização, no pluralismo dos sistemas de pensamento e na diversidade cultural, o sujeito contemporâneo tende a não mais se comprometer em levar adiante a tradição de cada família. Assim, observa Kaës (2005b), configura-se um mal-estar contemporâneo em termos de inseguranças e incertezas, já que o sujeito, sem a pretensão de levar adiante os valores próprios da família, não garante a esta o seu futuro como instituição singular, de sorte que não recebe em troca o apoio narcísico de investimento desse grupo. Disso decorrem instabilidades em torno das formações vinculares, porque, quando cada membro decide sobre seus passos, por meio da assimilação de novos valores e crenças, os membros da família se tornam menos identificados uns com os outros. São as diferenças marcantes entre as gerações. Por fim, como o contrato narcísico está associado à transmissão dos valores e dos ideais estruturantes de cada família, falhas no estabelecimento desse contrato acarretam igualmente problemas no processo de transmissão da vida psíquica.

Finalmente, Kaës (2005b) explica que o contrato de renúncia à realização direta dos fins pulsionais implica em um processo compartilhado de correcalque (corefoulement) entre a mãe e a criança. Essa renúncia supõe uma instância de enunciação dos interditos fundamentais e a constituição do superego na criança, como herdeiro do complexo de Édipo (Freud, 1924/1969), sustentado na culpa, no caso de esses interditos serem transgredidos, possibilitando ainda os processos sublimatórios. Kaës (2005b) enfatiza que, quando essas renúncias são possíveis, a sublimação se instala no lugar da repressão severa e cruel e torna possível o nascimento do desejo, do amor e da criação. Como consequência desse contrato, temos a garantia de que ele oferece a cada um a segurança necessária à formação do pré-consciente, ao trabalho do pensamento e à manutenção dos vínculos. Com efeito, Kaës (2005a) compreende o pré-consciente como uma instância intermediária, de passagem, de mediação e de transformação, responsável pelos processos de elaboração, mas também por processos que possibilitam a transformação da pulsão e das angústias em elementos de figuração, de representação e significação capazes de se articular com outros elementos figurativos do pensamento e, assim, produzir sentidos ao vínculo intersubjetivo.

Do contrário, em decorrência, quando falhas nas "garantias metassociais" se revertem em falhas no estabelecimento dos contratos inconscientes, é possível deduzir, com o autor, que "objetos não transformados, incorporados ou convertidos em atos, fabricam uma máquina antipensamento" (Kaës, 2005b, p. 249, tradução livre do autor). Ou seja, "objetos-pensamentos" brutos são evacuados de diversas formas (actings, identificação projetiva, violência associada às angústias primitivas e arcaicas etc.) ou poderão ser expressos pelas alucinações, pelas doenças psicossomáticas e por pensamentos ideológicos. Em busca de comprovar sua tese, Kaës (2011) sublinha que são essas as manifestações clínicas do sofrimento psíquico contemporâneo e, de maneira específica, aponta que falhas no contrato de renúncia à realização direta aos fins pulsionais têm ligações imediatas com "falhas ou defeitos nos dispositivos intersubjetivos de paraexcitação (Reizschutz) e de recalque na estruturação dos apoios da vida pulsional" (p. 20), desenvolvendo no lugar de objetos estáveis e confiáveis, "formações clivadas e não subjetivadas, desfavoráveis aos processos de simbolização e sublimação" (p. 20).

É importante ressaltar que o que Kaës (2005b) afirma não é uma negação ou recusa completa de assunção dos contratos, pactos e alianças, mas falhas, desregramentos ou defeitos nestes processos, porque, de fato, não supomos que essas transformações irão se converter em um retrocesso civilizatório, mas sim em mudanças na organização do psiquismo. Dessa maneira, supõe-se que não se trata de organizações psíquicas não mais estruturadas em torno do complexo deÉdipo, mas de modificações nessa estruturação, e por consequência, do superego. Nessa direção, Armony (2009) afirma que a diversidade de escolhas e a permissividade características da contemporaneidade culminaram por deslocar a organização psíquica outrora sob o reinado do superego para a de muitos pequenos egos, que provocam dúvidas, ansiedades, acúmulos e dispersões. Isso faz com que o homem contemporâneo viva "mais num regime de dissociações que de repressões" (p. 81), e esse acesso simultâneo aos pequenos "eus" 
provoca o sentimento de estar retalhado. Hoje, quando se "faz uma escolha é por tempo limitado, indo de um pequeno eu para outro" (p. 81). Essa situação pode ser angustiante, porque nunca haverá tempo para atender às demandas de todos os pequenos eus, até porque em muitos casos estas podem ser conflitantes entre si.

Outro resultado de movimentações na estruturação psíquica é trazido por Tisseron (2008), quando este compreende que a lógica das novas tecnologias e do mundo virtual tem favorecido no funcionamento psíquico o mecanismo de "recusa da realidade". A sociedade que se desenha não será mais do recalcamento, mas a da "recusa". Reflete o autor que, com desenvolvimento das novas tecnologias, sobretudo de comunicação, surgiram novos modelos de se relacionar que procuram, a todo custo, anular todo o tipo de separação ou afastamento. Além disso, a lógica do mundo virtual, por definição aquilo que tem (somente) o potencial de vir a ser, inaugura uma proposta de relação com o mundo onde cada um decide por si no que acreditar. Todo o sistema que abrange o mundo virtual, no qual tudo pode ser descartado num clique, aliado às imagens fabricadas que as novas tecnologias proporcionam, deixa ao encargo de cada um decidir o que é verdadeiro ou falso.

O mecanismo de defesa apontado por Tisseron (2008), diferentemente do conceito de negação, deve ser compreendido como associado antes de tudo à recusa da castração. Fassin (2006) explica que a diferença entre os mecanismos de defesa "recusa" (Verleugnung) e "negação" (Verneinung) assume a sua importância na distinção entre fatos e suas representações. O primeiro, o da "recusa", consiste numa ação psíquica que rejeita a realidade em razão de sua característica desagradável, insuportável e potencialmente traumatizante. É importante salientar que não faz a recusa de uma presença, mas de uma ausência, como no caso da ausência do pênis na mulher, o que leva a consequências mais graves para o processo de simbolização, pelo qual poderíamos representar a falta. O mecanismo da recusa realiza um processo de representação, porém, que não perdura em significado, porque a ausência tende a ser representada e recusada na sequência. Trata-se de um bloqueio, de uma clivagem do ego, a qual pode tomar formas patológicas, como no caso da psicose. No mecanismo de negação, entretanto, o processo psíquico permite a anunciação de maneira negativa de um conteúdo de um desejo inconsciente. De maneira geral, a negação preserva a representação da realidade e sua significação, mas ela separa os elementos mais desagradáveis. Assim, reconhece-se a realidade da qual se deseja reprimir e há um contato com a falta, ainda que estabelecido através da negação. $\mathrm{O}$ processo de afastamento do desagradável é menos profundo na negação do que na recusa, porque, nesta última, o desagradável simplesmente não assume nenhum sentido (Fassin, 2006).

\section{Conclusões}

Podemos pensar que o que Armony (2009) e Tisseron (2008) constatam, bem como o que os autores anteriormente apresentaram - Berger (2013), Costa (2012), Druzhinenko-Silhan (2013), Fidelis e Pereira (2012), Savietto e Cardoso (2009), Simões (2013) - está perfeitamente de acordo com o que Kaës (2005a,b) conjectura. Tudo leva a crer que as organizações psíquicas contemporâneas não mais se encontram mais sob o "reinado" do superego, já que esta instância psíquica é representativa de uma organização social estável e hierárquica. Como consequência principal, observamos falhas nos processos de elaboração, em que podemos tomar a cisão e/ou o mecanismo de recusa como mecanismos de defesa mais comuns. Quer dizer, assistimos a um afloramento de mecanismos de defesas pobres em capacidades de simbolização, em função de falhas nas "garantias metassociais" e "metapsíquicas", como assinalou Kaës (2005a,b).

Assim como Freud (1930/2006) salientou, o mal-estar na civilização resulta de sofrimentos em função das exigências de uma sociedade que irremediavelmente frustra. Conjecturando, se há algo que mudou desde Freud (1930/2006) é justamente a capacidade de lidar com a frustração - de assimilá-la, transformá-la, elaborá-la -, pois isso necessita de recursos psíquicos sofisticados, envolvendo elaboração em nível pré-consciente, e ampara-se em garantias metassociais e metapsíquicas estáveis (Kaës, 2005b), que não possuímos mais. Atualmente, é a capacidade de representar a falta que está em questão. Vivemos em uma sociedade que mais frustra do que disponibiliza recursos, elementos da cultura, para que os indivíduos consigam transformar suas dificuldades em algo construtivo.

É importante frisar que é possível que, no futuro, tudo se reorganize de outra forma, que estejamos apenas atravessando uma fase de transição. As socie- 
dades vêm se transformando às custas de dificuldades na reorganização de vidas e de estruturas psíquicas, mas podemos perceber benefícios também nestas modificações. Sociedades menos rígidas, mais democráticas e, sobretudo, que garantem maior liberdade ao sujeito. Se hoje a família não se organiza mais em torno do pai e com isso se movimenta a base na qual se alicerçava o complexo de Édipo, hoje temos novas possibilidades

\section{Referências}

Armony, N. (2009). Confrontando Winnicott com os azares da hipermodernidade. Cadernos de Psicanálise SPCRJ, 25(28), 77-119.

Aulagnier, P. (1979). A violência da interpretação. Rio de Janeiro, RJ: Imago.

Balsam, R. H. (2010). Where has oedipus gone? A turn of the century contemplation. Psychoanalytic Inquiry, 30(6), 511-519. doi:10.1080/07351690.2010.518532

Baudrillard, J. (2007). A sociedade de consumo. Lisboa: Edições 70.

Bauman, Z. (2004). Amor líquido: sobre a fragilidade dos laços contemporâneos. Rio de Janeiro, RJ: Jorge Zahar.

Bauman, Z. (2001). Modernidade líquida. Rio de Janeiro, RJ: Jorge Zahar.

Bauman, Z. (2009). Vida líquida. Rio de Janeiro, RJ: Jorge Zahar.

Berger, M. (2013). Que reste-t-il du role civilisateur du complexe d'Oedipe? Dialogue: Recherches sur le Couple et la Famille, 2(200), 73-84. doi:10.3917/dia.200.0073

Costa, A. P. A. (2012). A representação de pai em Lacan e Winnicott. Gestão Contemporânea, 2(2), 1-11.

Druzhinenko-Silhan, D. (2013). Autre chose quel'Oedipe? Neuropsychiatrie de l'Enfance et de l'Adolescence, 61(7-8), 441-447. doi:10.1016/j.neurenf.2013.09.004

Fassin, D. (2006) Du déni à la dénégation. Psychologie politique de la représentation des discriminations. In E. Fassin \& D. Fassin, De la question sociale à la question raciale? (pp. 131-157). Paris: Éditions La Découverte.

Fernandes, M. I. A. (2004). Algumas reflexões sobre a negatividade na construção dos laços sociais. Vínculo, 1(1), 9-16. Recuperado de http://pepsic. bvsalud.org/scielo.php?script=sci_arttext\&pi$\mathrm{d}=$ S1806-24902004000100003 de organização familiar e maior flexibilidade em torno das funções. Assim, é nítido que estamos sofrendo, mas parece que vale a pena continuarmos seguindo em busca de novos delineamentos mais saudáveis para a vida. Vivemos um momento sem precedentes e o futuro terá que ser inventado, isso dá trabalho, mas, por outro lado, que bom que existe uma possibilidade de inovação, de criação, de originalidade: isto é vida.

Fidelis, K. A. B., \& Pereira, M. R. (2012). Os imperativos da contemporaneidade e o não-lugar da adolescência. In Proceedins do $9^{\circ}$ Colóquio do LEPSI do IP/FE-USP (Retratos do mal-estar contemporâneo na educação), São Paulo. Recuperado de http:// www.proceedings.scielo.br/scielo.php?script=sci_ abstract\&pid=MSC0000000032012000100033\&ln$\mathrm{g}=\mathrm{en} \& \mathrm{nrm}=\mathrm{iso} \& \operatorname{lng}=\mathrm{pt}$

Freud, S. (1969). A dissolução do complexo de Édipo. In S. Freud, O ego o Id e outros trabalhos (Edição standard brasileira das obras psicológicas completas de S. Freud, Vol. 19; pp. 191-199). Rio de Janeiro, RJ: Imago. (Trabalho original publicado em 1924).

Freud, S. (2006). O mal-estar na civilização. In S. Freud, O futuro de uma ilusão o mal-estar na civilização e outros trabalhos (Edição standard brasileira das obras psicológicas completas de S. Freud, Vol. 21; pp. 67-148). Rio de Janeiro, RJ: Imago. (Trabalho original publicado em 1930).

Giddens, A. (1991). As consequências da modernidade. São Paulo, SP: Unesp.

Giddens, A. (2007). Mundo em descontrole: o que a globalização está fazendo de nós. Rio de Janeiro, RJ: Record.

Kaës, R. (2005a). Espaços psíquicos compartilhados: transmissão e negatividade. São Paulo, SP: Casa do Psicólogo.

Kaës, R. (2005b). La structuration de la psyché dans le malaise du monde moderne. In La santé mentale en actes (Etudes, recherches, actions en santé mentale en Europe, Vol 1 ; pp. 239-256). Paris : Ères.

Kaës, R. (2009). La transmission de la vie psychique et les contradictions de la modernité. In M. Sassolas, Transmissions et soins psychiques (pp. 21-35). Paris: Hors Collection.

Kaës, R, (2011). Um singular plural: a psicanálise à prova do grupo. São Paulo, SP: Loyola.

Kaës, R. (2014). As alianças inconscientes. São Paulo: Ideiais \& Letras. 
Laplanche, J. (Org.). (2004). Vocabulário de psicanálise: Laplanche e Pontalis. São Paulo, SP: Martins Fontes.

Lévi-Strauss, C. (1956). La famille. In C. Lévi-Strauss, Textes de et sur Claude Lévi-Strauss (p. 93-134). Paris: Gallimard.

Lipovetsky, G. (2004). Os tempos hipermodernos. São Paulo, SP: Barcarolla.

Moreira, J. O. (2004). Édipo em Freud: o movimento de uma teoria. Psicologia em Estudo, 9(2), 219-227. doi:10.1590/S1413-73722004000200008

Nicolson, P. (2012). Oedipus at work: a family affair? Psychodynamic Practice, 18(4), 427-440.

Richard, F. (2014). Le comples d'Oedipe existe-t-il toujours? L'identique et La difference: debat avec Françoise Héritier. Adolescence, 32(1), 23-46. doi: 10.3917 / ado.087.0023

Roudinesco, E. (2003). A família em desordem. Rio de Janeiro, RJ: Jorge Zahar.

Savietto, B. B., \& Cardoso, M. R. (2009). A drogadicçãona adolescência contemporânea. Psicologia em Estudo, 14(1), 11-19. doi:10.1590/S1413-73722009000100003

Setton, M.G.J. (2002). Família, escola e mídia:um campo com novas configurações. Educação e Pesquisa, 28(1), pp. 107-116. doi:10.1590/S1517-97022002000100008

Simões, F. I.W. (2013). As funções parentais e os vínculos familiares na atualidade. Omnia Saúde, 10(1), 10-25. Recuperado de http://www.fai.com.br/portal/ojs/ index.php/omniasaude/article/view/391/pdf

Steele, M. (2010). The quality of attachment and oedipal development. Psychoanalytic Inquiry, 30, 485-495. doi:10.1080/07351690.2010.518529

Tisseron, S. (2008). Virtuel, mon amour: penser, aimer, souffrir á l'ère des nouvelles technologies. Paris: Albin Michel.

\section{Sandra Aparecida Serra Zanetti}

Doutora. Docente da Universidade Estadual de Londrina, Londrina - PR. Brasil.

E-mail: sandra.zanetti@gmail.com

\section{Julia Archangelo Guimarães Höfig}

Graduada em Psicologia pela Universidade Estadual de Londrina, Londrina - PR. Brasil.

E-mail: julia.a.g@bol.com.br

Endereço para envio de correspondência:

Universidade Estadual de Londrina, Centro de

Ciências Biológicas, AC Jardim Bandeirantes. Jardim

Portal de Versalhes 1. Rodovia Celso Garcia Cid. Pr

445 Km 380. Campus Universitário. CEP 86057-970.

Londrina-PR. Brasil.

Recebido 14/12/2014

Aprovado 08/08/2016

Received 12/14/2014

Approved 08/08/2016

Recibido 14/12/2014

Aceptado 08/08/2016

Como citar: Zanetti S. A. S., \& Höfig J. A. G. (2016). Repensando o complexo de Édipo e a formação do superego na contemporaneidade. Psicologia: Ciência e Profissão, 36(3): 696-708. doi: 10.1590/1982-3703001652014

How to cite: Zanetti S. A. S., \& Höfig J. A. G. (2016). Rethinking the Oedipus complex and the superego formation in the contemporaneity. Psicologia: Ciência e Profissão, 36(3): 696-708. doi: 10.1590/1982-3703001652014

Cómo citar: Zanetti S. A. S., \& Höfig J. A. G. (2016). Repensando el complejo de Edipo y la formación del superyó en la contemporaneidad. Psicologia: Ciência e Profissão, 36(3): 696-708. doi: 10.1590/1982-3703001652014 